International Journal of Agriculture, Environment and Bioresearch

Vol. 5, No. 06; 2020

ISSN: $2456-8643$

\title{
EFFECT OF GA 3 ON GROWTH AND DEVELOPMENT OF TOMATOES UNDER WATER STRESS CONDITIONS
}

\author{
Ali M. Kalifa a , Idress A. Al Gehani ${ }^{\text {b* }}$, Adim A. Hamad ${ }^{c}$ and Sami A. Alasheebi ${ }^{\text {b }}$ \\ ${ }^{a}$ Department of Horticulture, Faculty of Agriculture, University of Omar Almukhtar, Albayda, Libya \\ ${ }^{b}$ Department of Plant Production, Faculty of Agriculture, University of Benghazi, Benghazi, Libya \\ ${ }^{\mathrm{c}}$ Minis try of Agriculture, Ajdabya, Libya \\ https://doi.org/10.35410/IJAEB.2020.5571
}

\begin{abstract}
Tomato plants (Lycopersicon esculentum Mill. cv. Rio Grand) grown in plastic bags were gradually exposed to water stress by reducing the amount of irrigation water by 0,20 and $40 \%$ to reach 100, 80 and $60 \%$ of field capacity (FC) during vegetative and reproductive phases. The plants were foliar sprayed by $\mathrm{GA}_{3}$ solution $(0,50$ and $100 \mathrm{ppm})$, three times at beginning of water stress treatment during vegetative stage. The results showed that the treatment of water stress ( $80 \%$ of FC) with a concentration of $50 \mathrm{ppm}$ of $\mathrm{GA}_{3}$ maintained the fresh and dry weight of shoots (FWS and DWS), while the values were increased with 100 ppm of $\mathrm{GA}_{3}$ treatment. In contrast, the fresh and dry weight of fruits (FWF and DWF) were decreased under the influence of water stress at $80 \%$ of FC, while the production under influence of water stress was aborted by $60 \%$ of FC treatment in presence or absence of GA3 treatment. The values of the fruit number $(\mathrm{FN})$ and the fruit volume (FV) were decreased due to effect of water stress treatment by $80 \%$ of FC, while the value of total soluble solids (TSS) in fruits was increased with this treatment. The period of maturity date (MD) was not affected by all treatments in this experiment, while the period of flowering date (FD) was shortened with a decrease in the applied field capacity. The water use efficiency (WUE) value of the shoots was increased under influence of water stress at $80 \%$ of $\mathrm{FC}$ with $\mathrm{GA}_{3}$ treatments, and on the contrary, the WUE value of fruits and plants decreased dramatically under the influence of this condition. The results showed that the role of $\mathrm{GA}_{3}$ under conditions of water stress did not have a positive effect on fruiting process despite the improvement in the growth of vegetative parts. It appears that the effect of treatment with $\mathrm{GA}_{3}$ on tomato plants depends mainly on the type and development of the growing part of the plant.
\end{abstract}

Keywords: Tomato; Lycopersicon esculentum Mill.; Water stress; $\mathrm{GA}_{3}$; Vegetative part; Reproductive phase.

\section{INTRODUCTION}

The decrease of water availability in arid and semiarid regions is becoming an important problem for agricultural producers. Hence, the researchers are interested to alleviate the severity of water deficiency in the agricultural lands. This effect of water deficit was depending on its severity and duration (Nahar and Gretzmacher, 2002).

The vegetable crops have widely affected such as tomato which is an important crop in the world. Many researchers have pointed out that tomato plants require a high quantity of water for optimal vegetative and reproductive development (Mitchell et al., 1991). As the water stress 
caused a reduction in the dry weight of tomato leaves by approximately $30 \%$ (Abou Hadid et al., 1986). The use of native cultivars of wild species in breeding programs may be an interesting practice for improving the tolerance of plants to water stress (Torrecillas et al., 1996), but there are many impediments that minify the favour of this object, such as low yield quality. In the last decades, another perspective arose based on the tolerance mechanisms of the cultivated tomatoes against water deficit. On the other hand, the application of new strategies and techniques in irrigation systems to improve water use efficiency in tomato culture (Garcia-Sanchez et al., 2016). Tavakkoli and Oweis (2004) indicated that the plants subjected to reducing irrigation lead to increase water use efficiency compared to fully irrigated plants. Improving WUE is necessary for securing environmental sustainability of food production in these areas (Medrano et al., 2015). In this way, that may be realised by imposing to the plant a progressive adaptation to drought condition, consequently, to obtain an acceptable yield with minimum water supply.

The effect of water stress is reflected in reducing the rate of cell division and elongation in plants (Torrecillas et al., 1995). Manifestations of drought tolerance for tomato plants is its ability to restore growth and dry matter accumulation to levels equivalent to those recorded for unstressed plants of the same age during vegetative phase (Boon, 1973; Abou Hadid et al., 1986; Kowithayakorn and Humphreys, 1987). Conversely, during the reproductive phase which has a major effect on the yield (Mitchell et al., 1991). The most sensitive periods of tomato to water stress are the stages of flowering and fruit enlargement (Srinivasa Rao et al., 2000), whereas Nuruddin et al. (2003) indicate that the application of water stress only during flowering stage resulted in better yields and quality than stress at other specific developmental stages or at all times. Somewhat, the fruits resist more than the flowers to dropping against water stress, such as bean (Mouhouche et al., 1998), for that it may become a disposable organ to study water stress tolerance.

Several studies, showed that the contents of IAA and $\mathrm{GA}_{3}$ in leaves decreased as the water stress increased, whereas the contents of ABA increased significantly under water stress conditions (Zhang et al., 2002). The researches indicated that it is possible to reduce the damage caused by water stress by increasing plant growth activity under stress conditions ( $\mathrm{Li}$ and van Staden, 1998), as adding substances that promote growth may have a positive effect in this regard, among the fertilizer materials and compounds, especially nitrogenous fertilizer and growth regulators such as auxins, gibberellins and cytokinins (Rimski-Korsakov et al., 2009; Ashraf et al., 2011). The role of growth regulators in increasing plant growth is known to specialists in this field, while their combined effect and relationship to water stress may provide more explanation that reduces the water stress problem in many areas with many plant species. Gibberellins are considered a growth regulators that are important in increasing plant growth activity under several conditions, they stimulate the division and elongation of cells in sub-apical of stems, which increases the vegetative growth of the plant. Gibberellic acid plays role on controlling fruit setting, pre-harvest fruit drop, increasing fruit yield and extending self-life (Mehta and Mathi, 1975). Gibberellins extend the stem and flowering in plants as well as preserve the chlorophyll of separated leaves, and also promote the formation of seedless tomato fruits (Misra and Biswal, 1980; Sawhney, 1984; Bewley, 1997). However, application of $\mathrm{GA}_{3}$ extended flowering and maturity time and increased fruit number per cluster, fruit set percentage and marketable fruit number per plant over the control (Gelmesa et al., 2012). GA 3 treatment (80 ppm) has increased tomato yield (Prasad et al., 2013), and increased the vegetative and 
reproductive growth of tomato (Tomar Saurabh et al., 2016), whereas Kumar et al. (2018) indicated that $\mathrm{GA}_{3}$ at $40 \mathrm{ppm}$ concentration showed significant effects on growth, flowering, yield and quality of tomato.

In fact, one way to improve production is to provide the complete water requirements of the plant, this will come with practical solutions to the problem of water stress caused by drought. Therefore, developing any strategy that leads to reducing this problem will necessarily lead to improving the water situation for the plant, which will be reflected in improving the quantity and quality of production.

Therefore, the aim of this paper was to investigate the effects of gibberellic acid $\left(\mathrm{GA}_{3}\right)$ on the growth and development of tomato fruits under applications of water stress during vegetative and reproductive phases.

\section{MATERIALS AND METHODS}

\section{Plant material, growth conditions and treatments:}

The experiment was carried out by cultivating the tomato plants (Lycopersicon esculentum Mill. CV. Rio Grand) in the research farm of the Faculty of Agriculture - University of Benghazi, seeds were sawing in a substrate consisting a 1:1:1 ratio of soil, sand and an organic matter in 30 litres plastic bags, a fertilization program has been applied by addition the essential nutrients during the growth and development stages of the plant.

Plants were grown under a plastic canopy to avoid the reach of rainfall in case of precipitation, at $14 \mathrm{~h}$ photoperiod, photosynthetic active radiation reached a daytime peak value of $1200 \mu \mathrm{mol} \cdot \mathrm{m}^{-2} \cdot \mathrm{s}^{-1}$, the temperature and relative humidity ranged to $30 / 18^{\circ} \mathrm{C}$ and $40 / 75 \%$ during day/night periods, respectively.

Treatments were initiated when the plants reached the first leaf stage with a vary levels of water stress and concentrations of gibberellic acid $\left(\mathrm{GA}_{3}\right)$. Plants were gradually exposed to water stress by reducing the amount of irrigation water by 0,20 and $40 \%$, to reach 100,80 and $60 \%$ of field capacity (FC). The plants were foliar sprayed by $\mathrm{GA}_{3}$ solution $(0,50$ and $100 \mathrm{ppm})$, three times in each other days at beginning of water stress treatment during vegetative stage. Amount of irrigation was adding according to the need of the plant and the change in the daily temperature with respecting the increase in the size of the plant due to growth. The amount of irrigation water was calculated according to modified method of Sibomana et al. (2013) by determining the difference in plant weight with the bag before and after each irrigation. So it has been taken into consideration the gradual increase in the amount of irrigation water needed by the plant to reach the whole percentage indicated of field capacity. Treatments have been continued until the beginning of the fruit maturity stage.

Plants designated for these measurements were cut off at the end of the vegetative stage, fresh weight of shoots (FWS) were measured for each treatment, these plants were dried three days in an oven at $65{ }^{\circ} \mathrm{C}$ (until there was no decrease in weight) for determination of dry weight (DWS) and percentage of dry weight (DWS\%) of shoots. The water use efficiency (WUE) was calculated by dividing the dry matter of plants, shoots and fruits by amount of irrigation water used. When the plants reached flowering stage; flowering date (FD) was determined. When the 


\section{International Journal of Agriculture, Environment and Bioresearch}

Vol. 5, No. 06;2020

ISSN: $2456-8643$

fruits reached maturity, the fruit numbers (FN), maturity date (MD), fruit volume (FV) and yield were calculated for each plant, and the fresh (FWF) and dry (DWF) weight of fruits were measured, as well as the total soluble solids of fruits (TSS) was determined.

The data presented are representative the mean of two independent experiments. The experimentation was conducted in four replicates, using factorial experimental $3 \times 3$ in completely randomized design, with the treatments of water stress and $\mathrm{GA}_{3}$. Data were subjected to analysis of variance using a two-way ANOVA. Differences among means of treatments were compared by Duncan's multiple range test at the 0.05 confidence level.

\section{RESULTS}

The exposure of tomato plants to water stress has reduced the FWS and DWS, with a decline of about $40 \%$ recorded under the influence of water deficit treatment at $60 \%$ of the field capacity (FC), and no significant effect of $\mathrm{GA}_{3}$ treatment with this condition of water stress $(60 \%$ of FC) (Table 1.). On the other hand, the interaction effect between water stress and $\mathrm{GA}_{3}$ treatments $(80 \%$ of FC and $50 \mathrm{ppm})$ has maintained the FWS and DWS, while the treatment of $80 \%$ of the FC with the concentration of $100 \mathrm{ppm}$ of $\mathrm{GA}_{3}$ has increased the average of FWS and DWS by $28 \%$ and $60 \%$ for both 50 and 100 ppm concentrations, respectively (Table 1.).

Table 1. Effect of $\mathrm{GA}_{3}$ and water stress treatments on fresh weight of shoots (FWS), dry weight of shoots (DWS), fresh weight of fruits (FWF), dry weight of fruits (DWF) (g/plant) and percentage of shoot dry weight (DWS\%) of tomato plants.

\begin{tabular}{|c|c|c|c|c|c|c|}
\hline \multicolumn{2}{|c|}{ Treatments } & \multicolumn{5}{|c|}{ Measurements } \\
\hline $\begin{array}{l}\text { Water Stress } \\
\text { (Field capacity \%) }\end{array}$ & $\begin{array}{l}\mathrm{GA}_{3} \\
(\mathrm{ppm})\end{array}$ & FWS & DWS & DWS \% & FWF & DWF \\
\hline \multirow{3}{*}{100} & 0 & $24.9^{\mathrm{bc}}$ & $4.3^{b}$ & $17.4^{\mathrm{ab}}$ & $31.5^{\mathrm{a}}$ & $5.18^{\mathrm{a}}$ \\
\hline & 50 & $23.6^{\mathrm{c}}$ & $3.3^{\mathrm{c}}$ & $14.0^{\mathrm{c}}$ & $7.8^{\mathrm{e}}$ & $1.27^{\mathrm{d}}$ \\
\hline & 100 & $38.2^{\mathrm{a}}$ & $5.7^{\mathrm{a}}$ & $14.8^{\mathrm{bc}}$ & $13.3^{\mathrm{d}}$ & $2.18^{\mathrm{c}}$ \\
\hline \multirow{3}{*}{80} & 0 & $22.3^{\mathrm{cd}}$ & $3.2^{\mathrm{c}}$ & $14.4^{\mathrm{bc}}$ & $23.4^{b}$ & $3.84^{\mathrm{a}}$ \\
\hline & 50 & $24.0^{\mathrm{c}}$ & $4.4^{\mathrm{b}}$ & $18.1^{\mathrm{a}}$ & $9.5^{\mathrm{e}}$ & $1.56^{\mathrm{d}}$ \\
\hline & 100 & $29.3^{\mathrm{b}}$ & $5.3^{\mathrm{a}}$ & $18.2^{\mathrm{a}}$ & $17.0^{\mathrm{c}}$ & $2.80^{\mathrm{b}}$ \\
\hline \multirow{3}{*}{60} & 0 & $14.8^{\mathrm{e}}$ & $2.5^{\mathrm{d}}$ & $18.0^{\mathrm{a}}$ & - & - \\
\hline & 50 & $15.8^{\mathrm{e}}$ & $1.9^{\mathrm{d}}$ & $12.1^{\mathrm{c}}$ & - & - \\
\hline & 100 & $17.3^{\mathrm{de}}$ & $1.9^{\mathrm{d}}$ & $11.8^{\mathrm{c}}$ & - & - \\
\hline
\end{tabular}

Each value represents mean of four replicates. Means followed by the same letter in each column are not significantly different by Duncan's multiple range test at 5\% level. 
The treatment with $\mathrm{GA}_{3}$ increased the DWS\% with $80 \%$ of FC being treated, and vice versa reduced it with $60 \%$ of FC being treated. Water stress of $80 \%$ of FC led to a $25 \%$ reduction in the FWF and DWF, also the treatments at 50 and 100 ppm of $\mathrm{GA}_{3}$ resulted in a $75 \%$ and $57 \%$ reduction in the FWF and DWF, respectively, with or without water stress (Table 1.). On the other hand, the treatment of $60 \%$ of FC completely aborted the reproduction process due to the fall of flowers and fruits at early stages of growth and development (Table 1.).

Water stress shortened the period required for the onset of flowering (FD), with the period from 75 to 71 and 65 days with water stress treated at $100 \%$ to $80 \%$ and $60 \%$ of FC, respectively (Table 2.). Water stress treatment ( $60 \%$ of FC) has aborted the reproduction phase by eliminating developing flowers and fruits, while water stress treatment ( $80 \%$ of FC) reduced the $\mathrm{FN}$ and $\mathrm{FV}$, and $\mathrm{GA}_{3}$ treatment reduced these measurements with water stress treatments of $100 \%$ (control) and $80 \%$ of FC (Table 2.). The period required to reach the stage of maturity of fruits (MD) has not been affected either by the treatment of water stress or by $\mathrm{GA}_{3}$, while the TSS of fruits has increased with the treatment of water stress ( $80 \%$ of FC) (Table 2.).

Table 2. Effect of $\mathrm{GA}_{3}$ and water stress treatments on flowering date (FD), maturity date (MD) (days), fruit number (FN), fruit volume (FV) $\left(\mathrm{cm}^{3}\right)$ and percentage of total soluble solids (TSS) of tomato plants.

\begin{tabular}{|c|c|c|c|c|c|c|}
\hline \multicolumn{2}{|c|}{ Treatments } & \multicolumn{5}{|c|}{ Measurements } \\
\hline $\begin{array}{l}\text { Water Stress } \\
\text { (Field capacity \%) }\end{array}$ & $\begin{array}{l}\mathrm{GA}_{3} \\
(\mathrm{ppm})\end{array}$ & FD & FN & MD & FV & TSS \\
\hline \multirow{3}{*}{100} & 0 & $75.3^{\mathrm{a}}$ & $4.33^{\mathrm{a}}$ & $39.5^{\mathrm{a}}$ & $57.6^{\mathrm{a}}$ & $13.75^{b}$ \\
\hline & 50 & $76.0^{\mathrm{a}}$ & $1.00^{\mathrm{e}}$ & $34.3^{\mathrm{ab}}$ & $14.2^{\mathrm{e}}$ & $14.50^{\mathrm{b}}$ \\
\hline & 100 & $72.3^{\mathrm{ab}}$ & $1.75^{\mathrm{cd}}$ & $32.2^{\mathrm{b}}$ & $24.2^{\text {cd }}$ & $14.75^{\mathrm{b}}$ \\
\hline \multirow{3}{*}{80} & 0 & $71.5^{\mathrm{ab}}$ & $3.25^{\mathrm{b}}$ & $37.3^{\mathrm{a}}$ & $42.7^{\mathrm{b}}$ & $20.00^{\mathrm{a}}$ \\
\hline & 50 & $69.7^{\mathrm{bc}}$ & $1.33^{\mathrm{de}}$ & $32.0^{\mathrm{b}}$ & $17.4^{\mathrm{de}}$ & $16.25^{\mathrm{ab}}$ \\
\hline & 100 & $67.3^{\mathrm{bc}}$ & $2.25^{\mathrm{c}}$ & $32.8^{\mathrm{b}}$ & $31.1^{\mathrm{c}}$ & $19.25^{\mathrm{a}}$ \\
\hline \multirow{3}{*}{60} & 0 & $65.0^{c}$ & - & - & - & - \\
\hline & 50 & $66.3^{\mathrm{bc}}$ & - & - & - & - \\
\hline & 100 & $66.3^{\mathrm{bc}}$ & - & - & - & - \\
\hline
\end{tabular}

Each value represents mean of four replicates. Means followed by the same letter in each column are not significantly different by Duncan's multiple range test at $5 \%$ level. 
The treatment with $100 \mathrm{ppm}$ of $\mathrm{GA}_{3}$ has clearly increased the WUE of shoots, this effect is enhanced under water stress conditions by $80 \%$ of $\mathrm{FC}$, while the WUE of shoots has significantly decreased under water stress conditions by $60 \%$ of FC (Figure 1.). There is no significant difference in the value of WUE for fruits under the influence of water stress $(80 \%$ of FC), while its value has been reduced to more than half with the use of $\mathrm{GA}_{3}$, and it should be noted that no data has been recorded with the application of water stress at $60 \%$ of $\mathrm{FC}$ due to the absence of production from fruits (Figure 1.). In regard to WUE of the plants, there has been a significant decrease in the value due to the treatment of water stress $60 \%$ of $\mathrm{FC}$, while the treatment of water stress $80 \%$ of the FC has had no effect (Figure 1.). On the other hand, the treatment with $\mathrm{GA}_{3}$ has preserved the WUE of the plants under water stress condition of $80 \%$ of FC, while reducing its value under the influence of $100 \%$ and $60 \%$ of the FC (Figure 1.).

Figure 1. Effect of $\mathrm{GA}_{3}$ and water stress treatments on water use efficiency (WUE) of plants, shoots and fruits of tomato

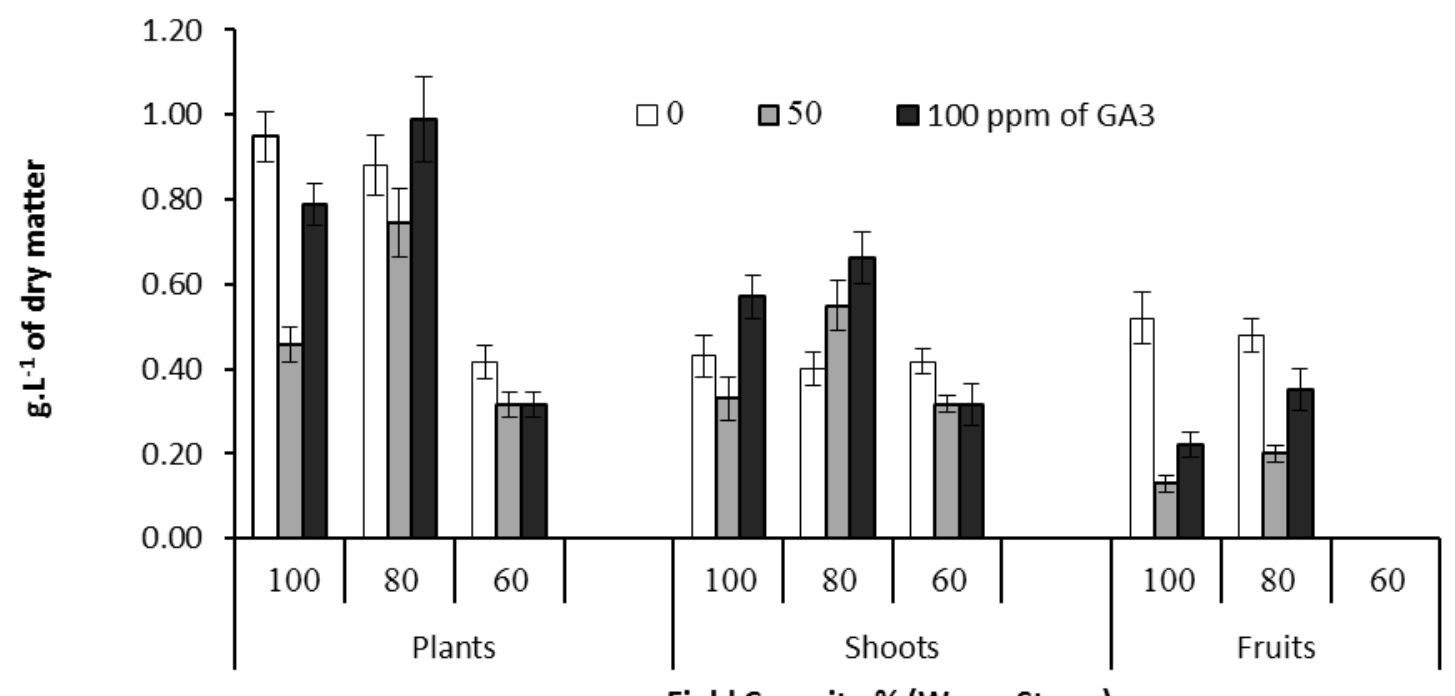

Field Capacity \% (Warer Stress)

\section{DISCUSSION}

The exposure of most plant species to water deficit conditions is one of the main causes that lead to reduction in biomass (Turner, 1979). The results of our experiment indicate that exposing the plants to a level of $60 \%$ of FC during their entire life cycle had a very severe effect on the reproductive growth, as a complete abortion occurred resulting in loss of fruit production (Table 1). Our results are consistent with what was indicated by Mitchell et al. (1991) and Srinivasa Rao et al. (2000) that the most sensitive period to water stress is the reproductive phase. This result is in contrast to the effect of water stress only applied during the fruiting phase 
(Nuruddin et al., 2003). Water stress had inhibited vegetative growth but enhanced fruit development (Nyabundi and Hsia, 2009). Whereas, the effect of water stress depends on the phase of growth and the duration of exposure (Nahar and Gretzmacher, 2002). The treatment of water stress $60 \%$ of $\mathrm{FC}$ obviously reduced the growth of plants in the vegetative growth, while it led to the loss of the reproductive growth. On the other hand, treatment with $\mathrm{GA}_{3}$ did not affect the direction of improvement of growth under water stress conditions (60\% of FC). The results indicated in table 1 that the treatment of $\mathrm{GA}_{3}$ had a positive effect represented in maintaining or increasing the growth of the shoots under the influence of water stress level $80 \%$ of FC. It appears that the application of water stress at $80 \%$ of $\mathrm{FC}$ allowed the emergence of the effect of treatment with $\mathrm{GA}_{3}$, which promoted the growth process in the plant by promoting FWS and DWS (Table 1). Perhaps, this level of water stress is close to the optimum state at which the water requirements of the plant become available. In contrast, the effect of $\mathrm{GA}_{3}$ on the reproductive growth was particularly negative, as the FWF and DWF were significantly reduced (Table 1.). This result did not agree with several studies indicating the effect of $\mathrm{GA}_{3}$ in extending the flowering phase subsequently increasing production (Bewley, 1997; Sawhney, 1984), and desirable effects on growth, flowering, yield and quality of tomato (Gelmesa et al., 2012; Kumar et al., 2018).

The manifestations of the reducing effect of water stress on the growth of the reproductive part in tomatoes were presented in the case of reducing the FN and FV (Table 2.). Although the FD under a water stress condition was reduced (such as from 75 to 71 days with $80 \%$ of FC), this effect was not reflected in the MD, which was not affected by water stress and/or $\mathrm{GA}_{3}$ treatments (Table 2.). In fact, one of the effects of exposing plants to water stress conditions is to reduce the period of FD and enhanced fruit development (Nyabundi and Hsia, 2009). On the other hand, our results are consistent with what was reported in previous research regarding the increase in the TSS of the fruits of plants subjected to water stress (Basit et al., 2020). High stress resulted in the highest soluble solids (Ozbahce and Tari, 2010). Table 2 indicates that the value of dissolved solids of fruits increased significantly under water stress conditions by $80 \%$ of the field capacity. Also, no clear effects of treatment with $\mathrm{GA}_{3}$ were shown in this measurement. Increasing the soluble solids has an important role in increasing the concentration of the compounds responsible for improving the flavor, which is reflected in raising the product quality.

Plant water use efficiency (WUE) is becoming a key issue in semiarid areas, where crop production relies on the use of large volumes of water (Medrano et al., 2015). Despite the increase in the WUE of the shoots due to treatment with $\mathrm{GA}_{3}$ under the level of water stress at $80 \%$ of FC (Fig. 1.), and this corresponds to what was mentioned by Tavakkoli and Oweis (2004), but this promising effect did not appear for WUE of the fruits that showed an obviously decrease in its value (Fig. 1.). The reduced effect of treatment with $\mathrm{GA}_{3}$ on growth in the flowering and fruiting parts indicated in table 1 and 2 must be reflected and expressed in a value of WUE of the fruits and plants.

\section{CONCLUSION}

There are many studies that agree with the fact that the plant's response to environmental conditions such as the abiotic stress, that is represented here by water stress depends on the type of growth and development that occurs during the plant's life cycle. The results of this 
experiment showed that the response of the vegetative growth to the treatment with $\mathrm{GA}_{3}$ under the conditions of moderate water stress was effective, in contrast to the response of the reproductive growth, which had severe damage, which led it to completely lose production. Despite several studies indicating the harmful effect of $\mathrm{GA}_{3}$ on flowering and fruiting process, we tried to find the beneficial role of $\mathrm{GA}_{3}$ in growth during the reproduction phase under the condition of water stress.

\section{ACKNOWLEDGEMENTS}

We thanks our colleagues for assistance in the field and laboratory, thanks to all the technicians for analysis of the samples.

\section{REFERENCES}

1. Abou Hadid A.F., El-Beltagy A.S., Smith A.R., Hall M.A. (1986). Effect of water stress on tomato at different stages of development. Acta Horticulturae. 190, 405-415.

2. Ashraf M., Akram N.A., Al-Qurainy F., Foolad M.R. (2011). Chapter five - Drought Tolerance: Roles of Organic Osmolytes, Growth Regulators, and Mineral Nutrients. advances in Agronomy. Academic Press. V. 111, 249-296.

3. Basit A., Hassnain M., Alam I., Ullah S.T., Shah S.A., Ullah I. (2020). Quality indices of tomato plant as affected by water stress conditions and chitosan application. Pure Appl. Biol. 9(2): 1364-1375.

4. Bewley J.D. (1997). Seed Germination and Dormancy. Plant Cell, 9, 1055-1066. http://dx.doi.org/10.1105/tpc.9.7.1055

5. Boon J. van der (1973). Influence of K/Ca ratio and drought on physiological disorders in tomato. Neth. J. Agric. Sci. 21, 56-67.

6. Garcia-Sanchez F., Simon-Grao S., Perez-Perez J.G, Gimeno V., Martinez-Nicolas J.J. (2016). Methods used for the improvement of crop productivity under water stress. Book Editor(s): Parvaiz Ahmad. John Wiley \& Sons, Ltd. Chapter 29.

7. Gelmesa D., Abebie B., Desalegn L. (2012). Regulation of tomato (Lycopersicon esculentum Mill.) fruit setting and earliness by gibberellic acid and 2,4- dichlorophenoxy acetic acid application. African Journal of Biotechnology. 11(51): 11200-11206.

8. Kowithayakorn L., Humphreys L. R. (1987). Effects of severity and repetition of water stress on seed production of Macroptilium atropurpureum cv. Siratro. Australian Journal of Agricultural Research. 38, 529-536.

9. Kumar S., Singh R., Singh V., Singh M.S., Singh A.K. (2018). Effect of plant growth regulators on growth, flowering, yield and quality of tomato (Solanum lycopersicum L.). Journal of Pharmacognosy and Phytochemistry. 7(1): 41-44.

10. Li L., van Staden J. (1998). Effects of plant growth regulators on the antioxidant system in callus of two maize cultivars subjected to water stress. Plant Growth Regulation. 24, 55-66. https//doi.org/10.1023/A:1005954532397

11. Medrano H., Tomas M., Martorell S., Flexas J., Hernandez E., Rossello J., Pou A., Escalona J., Bota J. (2015). From leaf to whole-plant water use efficiency (WUE) in complex canopies: Limitations of leaf WUE as a selection target. The Crop Journal. 3(3) 220-228. 
12. Mehta A.K., Mathi P.J. (1975). Effect of growth regulators on summer tomato (Lycopersicon esculentum Mill.). Haryana Hort. Sci.4(3/4): 167-176.

13. Misra A.N., Biswal U.C. (1980). Effect of phytohormones on chlorophyll degradation during aging of chloroplastsin vivoandin vitro. Protoplasma 105, 1-8.

14. Mitchell J.P., Shennan C., Grattan S.R., May D.M. (1991). Tomato fruit yields and quality under water deficit and salinity. Journal of the American Society for Horticultural Science. 116, 215-221.

15. Mouhouche B., Ruget F., Delecolle R. (1998). Effects of water stress applied at different phenological phases on yield components of dwarf bean. Agronomy Journal. 18(3), 197207.

16. Nahar K.,Gretzmacher R. (2002). Effect of water stress on nutrien uptake, yield and quality of tomato (Lycopersicon esculentum Mill.) under subtropical conditions. Die Bodenkultur. 53(1), 45-51.

17. Nuruddin M.M., Madramootoo C.A.,Dodds G.T. (2003). Effects of water stress at different growth stages on greenhouse tomato yield and quality. HortScience. 38(7): 1389-1393.

18. Nyabundi J.O., Hsia T.C. (2009). Effects of water stress on growth and yield of fieldgrown tomatoes. $\mathrm{H}$. Biomass partitioning between vegetative and productive growth. $E$. Afr. Agric. J. 55(2), 53-61.

19. Ozbahce A., Tari A.F. (2010). Effects of different emitter space and water stress on yield and quality of processing tomato under semi-arid climate conditions. Agricultural Water Management. 97(9): 1405-1410.

20. Prasad R.N., Kumar S.S., Yadava R.B., Chaurasia S.N.S. (2013). Effect of $\mathrm{GA}_{3}$ and NAA on growth and yield of tomato. Vegetable Science. 40(2): 195-197.

21. Rimski-Korsakov H., Rubio G., Lavado R.S. (2009). Effect of Water Stress in Maize Crop Production and Nitrogen Fertilizer Fate, Journal of Plant Nutrition. 32(4): 565-578, DOI:10.1080/01904160802714961

22. Sawhney V.K. (1984). Gibberellins and fruit formation in tomato: A review. Scientia Horticulturae. 22 (1-2): 1-8.

23. Sibomana I.C., Aguyoh J.N., Opiyo A.M. (2013). Water stress affects growth and yield of container grown tomato (Lycopersicon esculentum Mill) plants. G.J.B.B., 2 (4) 2013: 461-466.

24. Srinivasa Rao N.K., Bhatt R.M.,Sadashiva A.T. (2000). Tolerance to water stress in tomato cultivars. Photosynthetica, 38, 465-467.

25. Tavakkoli A.R.,Oweis T.Y. (2004). The role of supplemental irrigation and nitrogen in producing bread wheat in the highlands of Iran. Agricultural Water Management. 65(3):225-236

26. Tomar Saurabh, Dubey A.K., Singh Sanjiv Kr., Ujjwal Vivak. (2016). Effect of Different Levels of NAA, GA $\mathrm{GA}_{3}$ and 2, 4-D on Growth and Yield of Tomato (Lycopersicon esculentum Mill.). Annals of Horticulture. 9(1): 97-100.

27. Torrecillas A., Alarcón J.J., Domingo R., Planes J., Sánchez-Blanco M. J. (1996). Strategies for drought resistance in leaves of two almond cultivars. Plant Sci. 118:135143. 
International Journal of Agriculture, Environment and Bioresearch

Vol. 5, No. 06; 2020

ISSN: $2456-8643$

28. Torrecillas A., Guillaumeb C., Juan J. (1995). Water relations of two tomato species under water stress and recovery. Plant Science. 105,169-176.

29. Turner N.C. (1979). Drought resistance and adaptation to water deficits in crop plants. Stress physiology in crop plants. 343-372.

30. Zhang M.S., Xie B., Tan F. (2002) Relationship between changes of endogenous hormone in sweet potato under water stress and variety drought-resistance. Sci. Agric. Sin. 1:626630. 